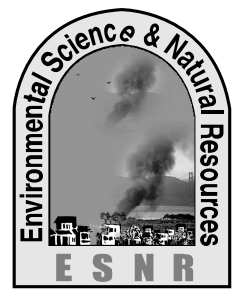

J. Environ. Sci. \& Natural Resources, 4(2): 89-97, 2011

ISSN 1999-7361

\title{
Assessing Environmental and Health Impact of Drought in the Northwest Bangladesh
}

\author{
N. C. Dey ${ }^{1}$, M. S. Alam¹, A. K. Sajjan², M A. Bhuiyan ${ }^{3}$, L. Ghose ${ }^{4}$, Y. Ibaraki ${ }^{5}$ and F. \\ Karim $^{1}$ \\ ${ }^{1}$ Research and Evaluation Division, BRAC, 75 Moakhali, Dhaka 1212 \\ ${ }^{2}$ Centre for Railway Engineering, Central Queensland University (CQU), QLD 4701, Australia \\ ${ }^{3}$ School of Civil, Environmental and Chemical Engineering, RMIT University, City Campus, \\ Melbourne, Australia \\ ${ }^{4}$ National Institute of Preventive and Social Medicine, Mohakhali, Dhaka 1212 \\ ${ }^{5}$ Yamaguchi University, 753-0831 Yoshida, Yamaguchi, Japan
}

\begin{abstract}
Drought, the result of regional climatic variability is one of the dominant threats to environment. This study focuses on the biophysical, environmental and health issues concerning drought occurrence in northwest region of Bangladesh. Using both primary and secondary data, the analysis revealed that, during the drought period, rainfall as the dominant factor of supplying surface water and normalizing the dryness of the nature was almost $46 \%$ lower than the previous (normal) years. Similarly, average monthly sunshine hours in the drought year was about $7 \%$ higher compared to that of the normal year. On an average, groundwater level declined more than one meter compared to the previous years. Thus, many of the tubewells turned dry or failed to supply the required quantity of water for household and irrigation purposes. A significant number of surface water bodies including ponds, ditches, canals and streams had little volume of low quality water. In normal years, almost all households used hand tubewells (HTWs) as the major source of drinking water, while in the drought period only $90 \%$ households could use HTW water since substantial proportion of the HTWs turned dry. People had to collect drinking and domestic water from far distance to meet the basic requirements. Increase in temperature and prevalence of severe dust during drought periods compared to the normal years caused different health hazards including dysentery and diarrhoea due to unsafe drinking water.
\end{abstract}

Key words: Drought, Environment, Groundwater, Health hazard, Northwest Bangladesh

\section{Introduction}

Drought as an environmental phenomenon is an integral part of climatic variability. The impact of drought not only leads to the shortage of water and food but also have a long-term environmental, socioeconomic and health impact on the population (Sheffield et al., 2009; WHO, 2011). It is a regional event and its occurrences are governed by regional climatic parameters like precipitation, evapotranspiration, temperature, etc. Droughts are becoming more frequent, more intense, more spatially extensive, and of longer duration (IPCC, 2010). So the characteristics and consequences of drought vary with respect to climatic regimes around the world (Iglesias et al., 2009; Murad, 2010; Shahid and Behrawan, 2008). Average occurrence of drought in Bangladesh is once in 2.5 years (Adnan, 1993; Hossain, 1990). Between 1960 and 1991, nineteen droughts have occurred in Bangladesh (Mirza and Paul, 1992). The National Water Management Plan (NWMP) considers occurrences of drought as a major water deficiency related issue in northwest region of Bangladesh (WARPO, 2001).

The northwest region of Bangladesh is characterized by its diverse landscape and semi-arid climate. The region has been experiencing recurrent below-average rainfall and thus lowering of groundwater levels in aquifers leading to water crisis for household, industry and agriculture. Agricultural land use and cropping pattern is changing over time to adapt with this emerging adverse situation. The region faced extreme drought during the year 1994, marked as the driest year in the contemporary periods. Besides, due to lack of proper knowledge and non-availability of modern technologies, farmers inappropriately lift water without caring ground sources and hence water table declines in many areas of Bangladesh. It is reported by Barind Multipurpose Development Authority (BMDA) that, groundwater (GW) level declined substantially during the last decade causing threat to the sustainability of water use for irrigation in the region. Although, the share of GW to total irrigated area was 77\% in 2007-08 (BBS, 2009), its sustainability is becoming a risk (Simonovic, 1997; Karim et al., 1990) in terms of quantity and quality in many parts of Bangladesh, northwest in particular.

The drought that occurred in 1994, particularly with a severe out-break in the north-western part of the country has left the people in an insecure condition. The situation turned worse due to abnormally low level of rainfall, which caused drying up of surface water bodies like canals, ponds, beels, and rivers in the region. The irrigation system was under severe stress as most of the shallow and hand tubewells (HTW) went dry and posed a serious threat to food grain production. The groundwater level declined to an abnormally low level compared 
to the levels in previous years. Most of the shallow tubewells were at inoperative or non- functioning stage.

Moreover, water shortage for domestic consumption was also identified as principal limit for the people during the dry season. Recurrent shortage of water has posed several impacts that can be categorized as economic, social, environmental and hygienic, etc. (Takara and Ikebuchi, 1997; Sajjan et al., 2002, WHO, 2011).

The available statistics indicate that, droughts in Bangladesh affect about 2.32 and 1.2 million hectares of cropped land annually during the Kharif (July to October) and Rabi (November to June) seasons, respectively [Ibrahim, 2001]. During the period of 1973-87, about 2.18 million tons of rice was damaged due to drought, while the extent of crop loss was 2.38 million tons due to flood in the same period (Paul, 1995).

Soil moisture generally remains low during the winter season (dry period) in Bangladesh. However, farmers grow winter crops (e.g., vegetables, boro rice, etc.) in an incremental rate mostly depending on the availability of groundwater to satisfy its demand. Monsoon rainfall has a direct effect on groundwater recharge. Due to low rainfall in 1994 winter season experienced a lowering of water table below pumping suction level. The predominantly shallow tubewell zones of northwest region of Bangladesh fell short of supplying its irrigation requirement from the underground source. Under the situation, it is of particular interest to assess the groundwater deficit prevailed in that winter season. It focuses mainly on the availability of dependable water resources in the aforesaid area with regards to supply for irrigation requirement.

Many studies show the drought-prone areas in Bangladesh in which northwestern part is indicated clearly a hard-hit region (Figure 1). Customarily the area has a high potential for agricultural production round the year. The area came under severe drought in 1994, and naturally was the focus of news media and public concern. However, the aim of the present study was therefore, to assess the impact of drought on availability of water resources and ultimate consequences as perceived by the inhabitants of northwest Bangladesh.

The specific objectives of the study were as follows: 1. to demarcate the level of fluctuations of groundwater table in the northwest region and to outline the differences in groundwater supply in drought situation in Bangladesh over the years.

2. to assess the experiences of the inhabitants on the use of water resource in drought years.

3. to understand the impact of drought on disease occurrence among the inhabitants in the study areas, and,

4. to markout the coping mechanism of the same population under water stress (drought) situation.

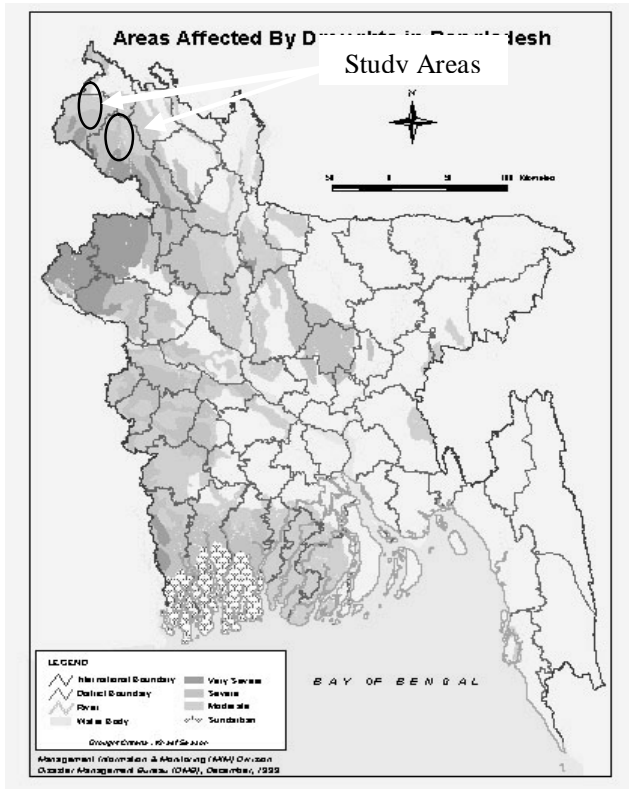

Figure 1. Drought prone regions of Bangladesh Source: www.sdnpbd.org/sdi/international_days 


\section{Methodology}

Data source: The study used both primary and secondary data.

(i) Primary data:

Data on the availability of groundwater, surface water, vegetation/plants conditions, temperature and dust were collected through conducting sample survey. In addition, data on health related problems occurred among the inhabitants and their coping mechanisms were also collected.

(ii) Secondary data:

Data on groundwater level, maximum temperature, annual rainfall, humidity, bright sunshine hours, etc for the study periods were taken from different Bangladesh Agriculture Development Corporation (BADC) offices; e.g. district meteorology office, Rangpur, and BRRI regional station in Rangpur, etc.

However, in order to compile the required primary data sample survey was carried out in two subdistricts namely Badarganj and Kishoriganj of Rangpur and Nilphamari districts. Extensive field visits were made for assessing environmental impacts of drought, which were by and large not available from any known source. The survey was conducted during May-December 1994.

\section{Questionnaire design}

The questionnaire was designed on the basis of local knowledge gained through field visit. It was aimed to make the questionnaire a target oriented and at the same time flexible enough to accommodate the specific impression of the respondents about the overall effect of drought in the areas. The questionnaire was pre-tested during the early field visits before being finalized. Few corrections and modifications were made during the preparation of the questionnaire.

\section{Sampling technique}

For getting a representative sample, a two-stage sampling procedure was followed. In the first stage, drought affected four unions were selected for the survey. These are Kishoriganj and Putimari unions from Kishoriganj sub-district and Radanagar and Ramanathpur unions from Badarganj sub-district. In the second stage, respondents were selected randomly from blocks of the selected unions. A total of 120 sample farmers were selected over the two subdistricts for taking interviews.

\section{Administration of the survey}

During face-to-face interview session by the trained enumerators, eight Block Supervisors (BSs, now called Sub Assistant Agriculture Officer, SAAO) from the respective areas were engaged for helping the interviews. Since the SAAOs are all trained in motivating and organizing the local people, their main task was to provide support to the framers in terms of knowledge on the occurrence and effect of drought.

\section{Data management and statistical analysis}

Filled-in questionnaires were edited and coded for computer entry under the close supervision. Twenty percent of the questionnaires were re-checked for being consistencies. The analysis was performed using SPSS 16.0 software. Both descriptive and inferential statistics were employed in analyzing the data. T-test compared the significance of mean differences between normal year and drought year for different climatic parameters. The difference was considered statistically significant at $\mathrm{p}<0.05$ (twotailed test) level.

The mean test was done employing the following formula:

$t=\frac{\overline{x_{1}}-\overline{x_{2}}}{\sqrt{\frac{s_{1}^{2}}{n_{1}}+\frac{s_{2}^{2}}{n 2}}}$

Where,

$$
\begin{aligned}
& S_{1}^{2}=\frac{1}{n_{1}-1} \sum\left(x_{i}-\bar{x}\right)^{2} \\
& S_{2}^{2}=\frac{1}{n_{2}-1} \sum\left(x_{j}-\bar{x}\right)^{2}
\end{aligned}
$$

$\mathrm{i}, \mathrm{j}=1,2,3 \ldots \ldots \mathrm{n}$

\section{Results and discussion}

\section{Differences in weather factors between normal} and drought years

Data on different climatic parameters (e.g. rainfall, temperature, sunshine hours, etc.) for different years were analyzed to visualize the magnitude of differences between normal and drought years. Among others, rainfall as the dominant factor of supplying surface water and normalizing the dryness of the nature was much low $(1163 \mathrm{~mm})$ in 1994 compared to that of the previous years, in other words, the rainfall in the previous (normal) year was almost $46 \%$ higher. This difference was highly significant. At the similar notion, the average monthly sunshine hours in the drought year (1994) was about 7\% higher compared to that of the 
previous (normal) years $(<0.01)$. This difference was also statistically significant (Table 1). These evidences on climatic factors and the pertinent analysis clearly imply that, in the year 1994, the northwest region of Bangladesh experienced severe dry and drought environment.

Table 1. Level of differences in different climatic parameters in drought year and normal years

\begin{tabular}{lllll}
\hline Years & $\begin{array}{l}\text { Av. max. temp } \\
(\text { in C }\end{array}$ & $\begin{array}{l}\text { Total } \\
(\mathrm{mm})\end{array}$ & $\begin{array}{l}\text { rainfall } \\
\text { Monthly } \\
\text { average } \\
\text { sunshine } \mathrm{hrs}\end{array}$ & $\begin{array}{l}\text { Solar radiation } \\
\left(\mathrm{gm}-\mathrm{cal}_{\mathrm{cm}} / \mathrm{day}\right)\end{array}$ \\
\hline $\begin{array}{l}\text { Normal year } \\
\text { three years average) }\end{array}$ & 32.04 & 1699.15 & 83.67 & 4323.5 \\
$\begin{array}{l}\text { Drought year (1994) } \\
\begin{array}{l}\text { Mean difference } \\
\text { (i.e. \% increase/decrease }\end{array}\end{array}$ & 33.51 & 1163.32 & 89.22 & 4481.0 \\
$\begin{array}{l}\text { in 1994) } \\
\mathrm{p}=(\mathrm{T}<\mathrm{t})\end{array}$ & 4.88 & 46.08 & 6.63 & 3.28 \\
& 0.073 & 0.032 & 0.053 & 0.013 \\
\hline
\end{tabular}

\section{Groundwater level}

Time series plots (1986 to 1995) show that groundwater levels were dropped more than 1 meter during 1994 as appears in Figures 2 and 3. During the field visit it was observed that, groundwater extraction technology was predominantly by shallow tubewells. It was also observed that in the drought year (1994), groundwater levels were much below than previous years. However, groundwater levels at Ramanathpur and Kishoriganj were about 6 meter below than the ground surface (GS). Groundwater levels were about 4 to 5 meter below the land surface. So it was expected that the extra drawdown of the water level in the vicinity of the pumping wells would produce the water level to go beyond suction limit (7 meter below the pump level) as a result of tubewell operation. This is why most of the tubewells in that region could hardly supply adequate irrigation water in the 1994 dry period. This might be because of more lifting of groundwater for irrigation and domestic purposes in the dry period. Besides, short rainfall also causes less recharge of groundwater. However, more than $86 \%$ of lifted water is used for agricultural purposes (Hoque et al., 2006). Some of the recent studies showed that groundwater level in some areas of Bangladesh falls between 5-10 meter in dry season and most of the tubewells fail to lift sufficient water (Dey and Ali, 2010).
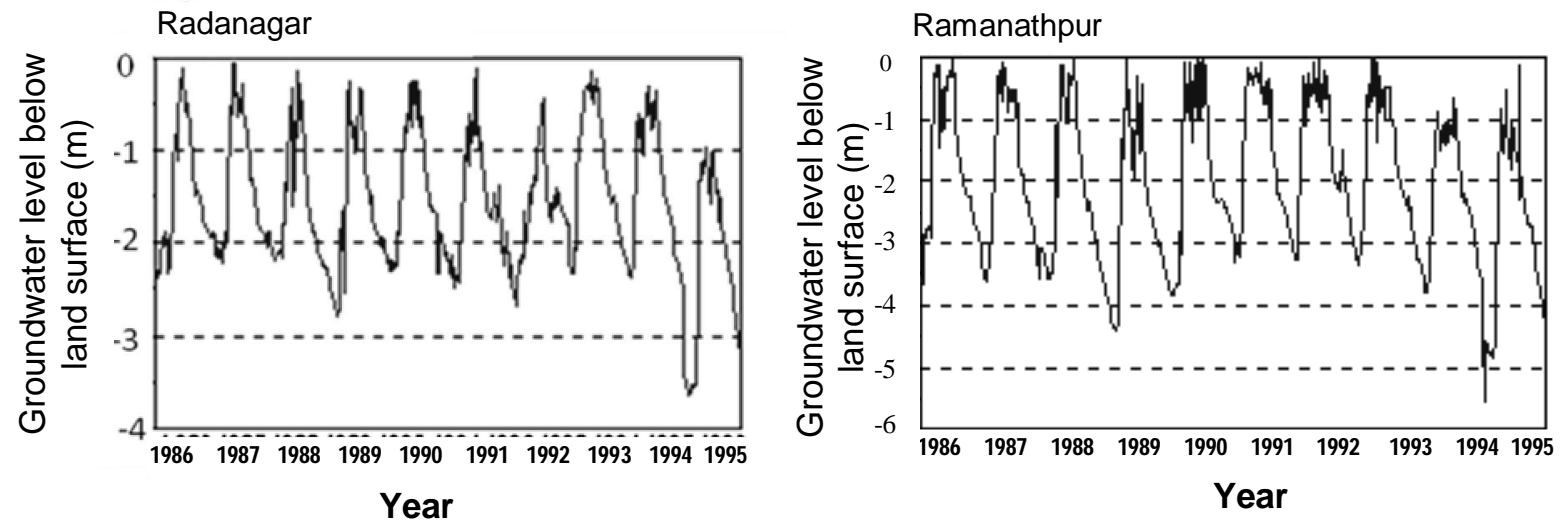

Figure 2. Groundwater levels below land surface at different stations in Badarganj sub-district 

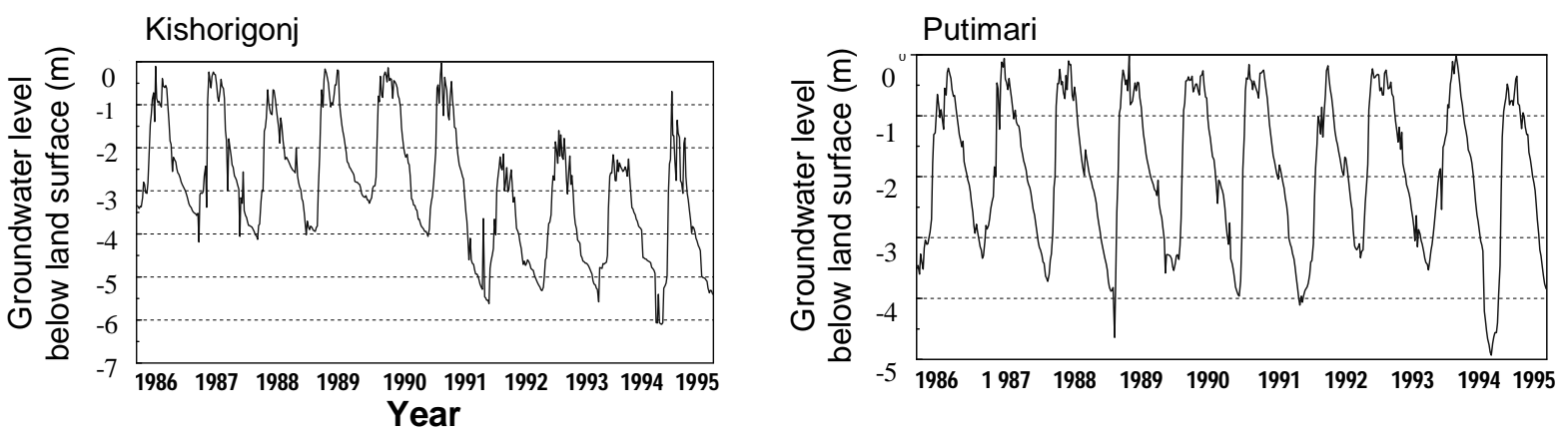

Figure 3. Groundwater levels below land surface at different stations in Kishoreganj sub-district

Inhabitants' experiences on the availability of surface and groundwater in drought year

The sample respondents were asked to provide with the issues on availability of surface and groundwater in the drought in 1994. Data in Table 2 indicate that all the respondents of both the sub-districts agreed about decrease in availability of groundwater and surface water compared to that of previous years.

Table 2. Respondents' opinions regarding availability of surface water and groundwater during 1994-95

\begin{tabular}{ccccccc}
\hline & \multicolumn{3}{c}{$\%$ respondents opined } \\
\cline { 2 - 6 } Water sources & \multicolumn{3}{c}{ Kishoriganj } & Badarganj \\
\cline { 2 - 6 } & \multicolumn{3}{c}{ Water availability } & Water availability \\
\cline { 2 - 7 } & Increased & Decreased & No change & Increased & Decreased & No change \\
\hline Groundwater & 0 & 100 & 0 & 0 & 100 & 0 \\
Surface water & 0 & 100 & 0 & 0 & 100 & 0 \\
\hline
\end{tabular}

\section{Inhabitants' experiences on the use of water in} drought year and normal years

Local people shared their impression that during drought period most of the tubewells could not supply adequate quantity of water as was available in the previous years. Many hand tubewells (HTWs) went dry and out of operation. People were experiencing the scarcity of clean water in the drought year, many of the respondents could not use pond or other surface water bodies due to drying up or having too little volume of water at the bottom. In Badarganj area, $100 \%$ respondents reported that in normal situation of 1993, HTWs were the major source of drinking water, while in drought year 1994 only $90 \%$ of them could use HTWs for the same purpose (Table 3). Nearly $37 \%$ respondents reported that water for drinking and bathing of cattle was usually from pond in the normal year, but a different picture appeared in the drought year. i.e. due to drought only about $18 \%$ respondents were able to use pond water for the same purpose.

Table 3. Respondents' experiences on the use of water in drought year and normal year at Badarganj

\begin{tabular}{lcccccc}
\hline & \multicolumn{5}{c}{$\%$ respondents opined } \\
\cline { 2 - 7 } Water sources & \multicolumn{3}{c}{ Drought year } \\
\cline { 2 - 7 } & \multicolumn{3}{c}{ Water uses } & \multicolumn{2}{c}{ Normal year } \\
\cline { 2 - 7 } & Drinking & Bathing & $\begin{array}{c}\text { Cattle's } \\
\text { bathing }\end{array}$ & Drinking & Bathing & $\begin{array}{c}\text { Cattle's } \\
\text { bathing }\end{array}$ \\
\cline { 2 - 7 } & 0 & 0 & 6.7 & 0 & 0 & 7 \\
Piver Water & 0 & 0 & 18 & 0 & 8.3 & 37 \\
HTW & 93 & 93 & 50 & 100 & 92 & 47 \\
STW/DTW & 7 & 7 & 17 & 0 & 0 & 3 \\
\hline
\end{tabular}


In Kishoriganj, dug well and ponds were the secondary sources of bathing for about $28.3 \%$ and $6.7 \%$ inhabitants, respectively in 1993 . But due to drought in 1994, nobody could use pond water for bathing and only $3.3 \%$ people used dug well for this purpose (Table 4). It is worth mentioning that, in 1993 pond was the main source for drinking and bathing of cattle since almost $35 \%$ respondents used this, but very distinctly the use of pond water for the same purpose decreased to $10 \%$ in drought year.

Table 4. Respondents' experiences on the use of water in drought year (DY) and normal year (NY) at Kishoriganj

\begin{tabular}{|c|c|c|c|c|c|c|}
\hline \multirow{4}{*}{$\begin{array}{l}\text { Water } \\
\text { sources }\end{array}$} & \multicolumn{6}{|c|}{$\%$ respondents opined } \\
\hline & \multicolumn{3}{|c|}{ Drought year } & \multicolumn{3}{|c|}{ Normal year } \\
\hline & \multicolumn{3}{|c|}{ Water uses } & \multicolumn{3}{|c|}{ Water uses } \\
\hline & Drinking & Bathing & $\begin{array}{l}\text { Cattle's } \\
\text { bathing }\end{array}$ & Drinking & Bathing & $\begin{array}{l}\text { Cattle's } \\
\text { bathing }\end{array}$ \\
\hline Dug well & 0 & 3.5 & 1.7 & 0 & 28.3 & 8.3 \\
\hline River Water & 0 & 3.5 & 1.7 & 0 & 3.5 & 7 \\
\hline Pond & 0 & 0 & 10 & 0 & 7 & 33 \\
\hline HTW & 93 & 93 & 28.3 & 100 & 62 & 28 \\
\hline STW/DTW & 0 & 0 & 43 & 0 & 0 & 12 \\
\hline
\end{tabular}

Distance walked to fetch water for different purposes both in drought year (DY) and previous normal year (NY)

Due to scarcity of surface water and decline of groundwater level, people had to collect water for drinking and bathing from distant areas in order to maintain their water requirement. In Badargonj, people had to walk about 80-100 meter in DY compared to the NY (only 10 meter) year for bathing through using pond water and STW/DTW (Shallow and Deep Tube Well) water. Besides, for bathing of their cattles, people had to walk about 200 meters for river or pond water, 100 meters for STW/DTW water in DY (1994). However, usually they did not walk such distance in the NY for cattle's bath using river or pond or tubewell water (Fig. 4). In Kishoriganj, people had to walk far distance (200 meters) for bathing water from dug well in DY compared to no walk in the NY. However, in DY, people walked far distance i.e. nearly half kilometer for cattle's bathing using river water or tubewell water and 400 meters for pond water (Fig. 5).

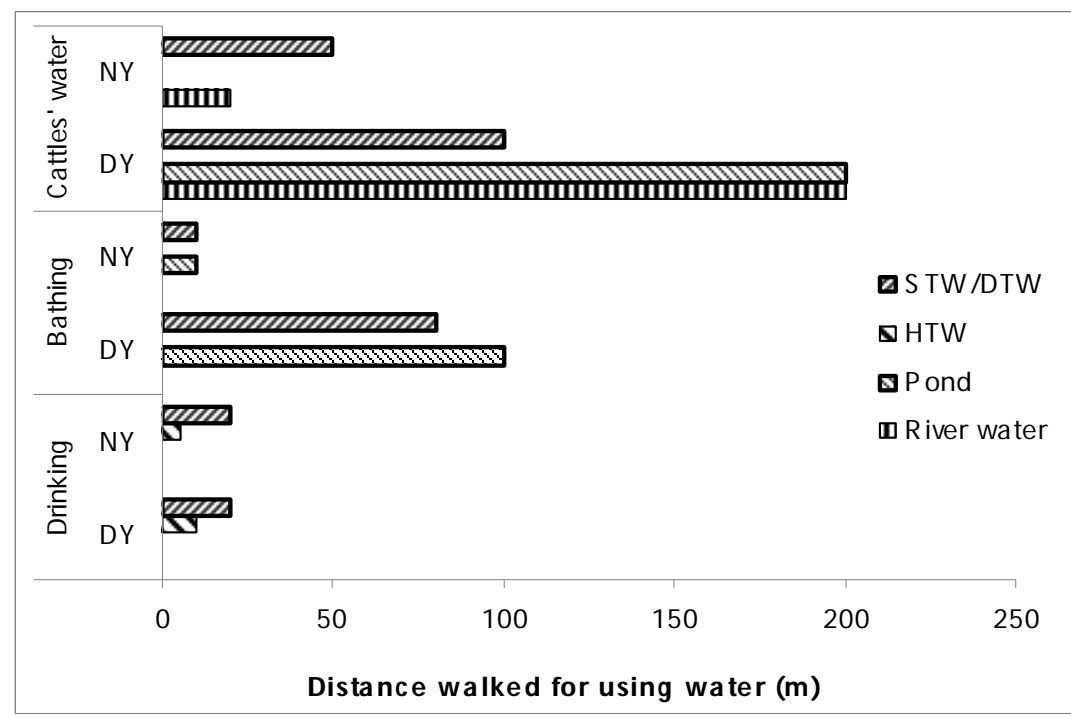

Fig.4. Distance walked for using water for different purposes both in drought year and previous year at Badarganj 


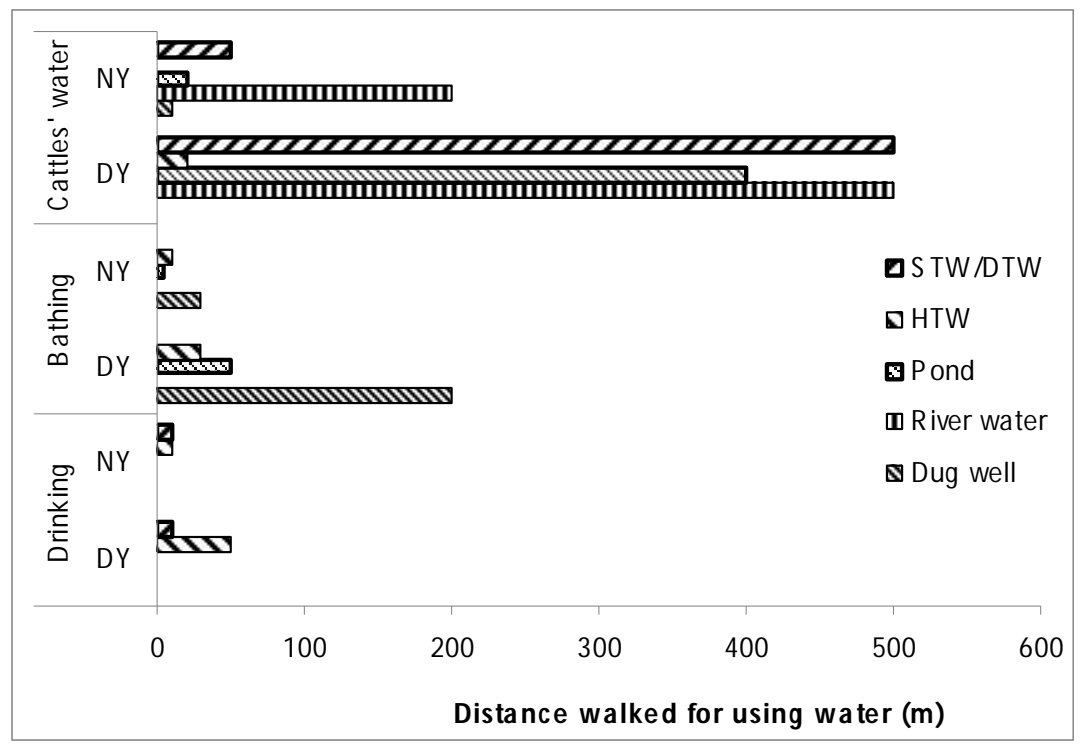

Fig. 5. Distance walked for using water for different purposes both drought year and previous year at Kishoriganj

\section{Health sufferings due to drought}

Results also showed that, existing water sources, mostly rivers and stagnant ponds, were contaminated due to drought. Hence, outbreaks of bloody diarrhoeal disease have affected both adults and children (WHO, 2002). Health related problems as was observed in Kishoriganj and Badarganj are presented in Table 5. In NY the farmers in Kishoreganj and Badarganj suffered mainly from fever. But in DY, sufferings from both dysentery and diarrhea were recorded to a drastically higher level. In Kishoriganj, only $5 \%$ of the respondents suffered from diarrhea in the NY, while about $28 \%$ people suffered from this disease in the DY. At the similar notion, however, outbreaks of dysentery was also recorded to an abrupt by higher level both in Kishoriganj and Badarganj during the DY compared to that of the NY (Table 5). In Badarganj, the proportion of inhabitants (34\%) suffered from dysentery in DY, which was much higher compared to those suffered in NY (only 6\%) implying that the occurrence of dysentery in the drought period was considerably high. Analysis further implied that, in Badarganj only $34 \%$ of the sample respondents made consultation with the physicians during the NY, while in drought period about $58 \%$ of the respondents had to consult with the doctors since the level of different ailments among them were substantially higher in the DY. The World Health Organization (2011) also identified the impact of drought leads to water and food shortages and is likely to have a long-term environmental and jeopardize the health of people. Besides, study shows that drought as a naturally occurring climate phenomenon that has impacts on human and environmental activity (Sheffield et al. 2009).

Table 5. Level of health hazards among the sample population in normal and drought years

\begin{tabular}{lcccc}
\hline Indicators & \multicolumn{4}{c}{ K of respondents } \\
\cline { 2 - 5 } & Drought year & Normal year & Drought year & Normal year \\
\cline { 2 - 5 } & & & & \\
Malaria & 0 & 0 & 0 & 0 \\
Diarrhea & 33 & 7 & 23 & 3 \\
Typhoid & 2 & 5 & 2 & 3 \\
Fever & 67 & 86 & 54 & 70 \\
Dysentery & 50 & 10 & 55 & 10 \\
Other & 5 & 2 & 8 & 5 \\
No Disease & 0 & 5 & 3 & 57 \\
Consult with Doctors & 100 & 76 & 86 & \\
\hline
\end{tabular}




\section{Conclusions}

Due to insufficient or poorly distributed rainfall drought occurs frequently in the northwest region of Bangladesh. The present analysis revealed that in the context of drought in 1994, on an average groundwater levels declined more than one meter both in the Kishoriganj and Badarganj areas. Badarganj was more affected area than Kishoriganj. Most of the tubewells could not supply adequate quantity of water and about 60-70\% HTWs went out of operation. Local people could not use ponds or other surface water bodies due to drying up or having little volume of water with poor quality and unhygienic status. Moreover, in normal years almost $100 \%$ farm households used HTWs as major source of drinking water, while in the drought period only about $90 \%$ households could use HTW water since substantial portion of those turned-dry and as such the inhabitants had to use unsafe drinking water from other surface water bodies. Aside from the problems raised for human being due to water scarcity in DY, rearing livestock also appeared to be a serious problem. In the NY, more than one-third households could use pond water for drinking and bathing of cattles, while in the DY only $18 \%$ households were able to use pond water for the same purpose. The abnormalities in the physical environment in the form of increased temperature, hot and dusty air, etc. also appeared in DY. Besides, in DY the level of health related sufferings particularly dysentery and dirrhoea increased to a higher level most probably due to unsafe water use, and consequently, much higher proportion of respondents (about 60\%) were compelled to consult the doctors regarding health problems.

\section{Acknowledgement}

We a sincerely acknowledge the financial support from the Netherlands Government. We are grateful to the participants who provided valuable information for this study.

\section{References}

Adnan, S. 1993. Living without floods: lessons from the drought of 1992, Research and Advisory Services, Dhaka.

Bangladesh Bureau of Statistics (BBS). 2009. Statistical yearbook of Bangladesh. Statistics Division, Ministry of Planning, Government of the Peoples' Republic of Bangladesh. Dhaka.

Brammer, H. 1987. Drought in Bangladesh: lessons for planners and administrators. Disaster, 11(1):30-33.

Burnash, R. J. C. and Ferral, R. L. 1972. Generalized hydrologic modeling, a key to drought analysis. proc. of the second international symposium on hydrology, Fort Colins, Colo., U.S.A., pp.50314.

Dey N. C. and Ali, A. R. M. M. 2010. Changes in the use of tubewell water and water safety measures in rural Bangladesh-a midline assessment, BRAC unpublished report, RED, BRAC, Dhaka.

Hoque, B. A.; Hallman, K.; Levy, J.; Bouis, H.; Ali, N.; Khan, F.; Khanam, S.; Kabir, M.; Hossain, S. and Alam, M. S. 2006. Rural drinking water at supply and household levels: quality and management, Int. J. Hygiene Environ Health, 209(5):451-60.

Ibrahim, M. A. 2001. Application of agro-ecological zones database in drought management and water availability assessment, Bangladesh Agricultural Research Council, Farmgate, Dhaka.

IPCC. 2010. World climate report-global drought pattern.

www.worldclimatereport.com/index.php/2010/02 /24/update-on-global-drought-patterns-ipcc-

Karim, Z.; Ibrahim, A. M.; Iqbal, A. and Ahmed, M. 1990. Drought in Bangladesh agriculture and irrigation schedules for major crops, Bangladesh Agricultural Research Council (BARC), Soils Publication, 34:11.

Simonovic, S. P. 1997. Risk in sustainable water resources management. In Sustainability of water resources under increasing uncertainties, IAHS Pub. No. 240.

Suprato, A. 2001. Land and water resources development in Indonesia. Regional office for Asia and the Pacific: Food and Agriculture Organization.

Mirza, MQ. and Paul, S. (1992). Prakritik durgojob o Bangladesh paribesh (Natural disaster and environment in Bangladesh), Centre for Environmental Studies and Research, Dhanmondi, Dhaka.

Murad, H. 2010. Agricultural and meteorological drought assessment using remote sensing and GIS in north-west region of Bangladesh, Unpublished M.S. thesis, Department of Water Resources Engineering, Bangladesh University of Engineering and Technology, Dhaka.

Hossain, M. 1990. Natural calamities, instability in production and food policy in Bangladesh, The Bangladesh Development Studies (BDS); Bangladesh Institute of Development Studies, 18(1).

Iglesias, A.; Garrote, L.; Cancelliere, A.; Cubillo, F. and Wilhite, A. D. 2009. Coping with drought risk in agriculture and water supply systems, drought management and policy development 
in the Mediterranean, Advances in Natural and Technological Hazards Research, 26.

Paul, B. K. 1995. Respondent and public responses to the 1994-95 drought in Bangladesh: a case study. Manhattan: Kannsas State University, USA.

Sajjan, A. K.; Muhammed, A.; Bhuiyan and Nepal Dey C. 2002. Impact of 1994-95 drought in the northwest of Bangladesh through questionnaire survey, Proc. of the $2^{\text {nd }}$ annual paper meet of Agric. Eng, Division, Institution of Engineers, Bangladesh, 1:31-5.

Shahid, S. and Behrawan, H. 2008. Drought risk assessment in the western part of Bangladesh, J. of Natural Disaster, 46(3):391-413.

Sheffield, J.; Andreadis, K. M.; Wood, E. F. and Lettenmaier, D. P. 2009. Global and continental drought in the second half of the twentieth century: severity-area-duration analysis and temporal variability of large-scale events, J. Climate, 22:1962-81.

Takara, K. and Ikebuchi, S. 1997. Japan's 1994 drought in terms of drought duration curve. Proc. of the fifth symposium of Water Resources, p. 467-77.

www.amazon.com/exec/obidos/ASIN/0415168 333/largeprintreview/104-5717184-7999143

Water Resources Planning Organization. 2001. Draft development strategy, National Water Management Plan, Dhaka.

World Health Organization. 2002. Drought related health problems in Ethiopia: Ministry of Health, pp.1-39.

World Health Organization. 2011. Health action in crisis-drought-natural disaster. 